\title{
EDITORIAL
}

\section{Regional Climate Downscaling over Asia-Pacific Region}

\author{
Hyun-Suk Kang ${ }^{1}$, Fredolin Tangang ${ }^{2}$, and R. Krishnan ${ }^{3}$ \\ ${ }^{I}$ National Institute of Meteorological Sciences, Korea Meteorological Administration, Jeju, Korea \\ ${ }^{2}$ School of Environmental and Natural Resource Sciences, Universiti Kebangsaan Malaysia, Kuala Lumpur, Malaysia \\ ${ }^{3}$ Centre for Climate Change Research, Indian Institute of Tropical Meteorology, Pune, India
}

(C) The Korean Meteorological Society and Springer 2016

Subsequent to publication of the Fifth Assessment Report of the Intergovernmental Panel on Climate Change (IPCC AR5) in 2013, the needs for downscaled climate information on regional-to-local scale for impact and risk assessments have become critical across scientific working groups as well as stakeholders (Stocker et al., 2015). In this context, downscaling techniques with a regional climate model (RCM) and empirical statistical downscaling (ESD) methods play an important role to overcome limitations of atmosphere-ocean coupled general circulation models (AOGCMs). Even though the history of regional climate modeling goes back to the late 1980s (e.g., Dickinson et al., 1989) and its collaborative studies for multi-model ensembles back to the 1990s (e.g., Takle et al., 1999; Christensen et al., 2007; Fu et al., 2005), they mainly focused on a specific domain within their own framework (e.g., domain size, resolution, large-scale driving force, target period, and etc.) such as North America, Europe, and Asia, but not on all across the globe.

The coordinated regional downscaling experiment (CORDEX) (http://www.cordex.org) has been launched to serve as a catalyst for advancing the science and application of regional climate downscaling through active global partnership sponsored by World Climate Research Program (WCRP) (Giorgi et al., 2009). It aims to provide a framework more accessible to a broad scientific community with maximum use of results. Therefore, the CORDEX domains, which are 14 in number, cover the majority of land areas of the world including Arctic and Antarctic. The Asia-Pacific region consists of four domains: South Asia, Southeast Asia, East Asia, and Australia (Fig. 1). This issue composed of 10 scientific articles achieved from each CORDEX community of Asia-Pacific region. It is believed that the papers in this issue will stimulate further collaboration among regional downscaling groups of each community so that could contribute to be a milestone of successful accomplishment toward the next phase of CORDEX.

Corresponding Author: Hyun-Suk Kang, National Institute of Meteorological Sciences, Korea Meteorological Administration, 33 Seohobuk-ro, Seogwipo-si, Jeju 63568, Korea.

E-mail: hyunsuk306.kang@gmail.com

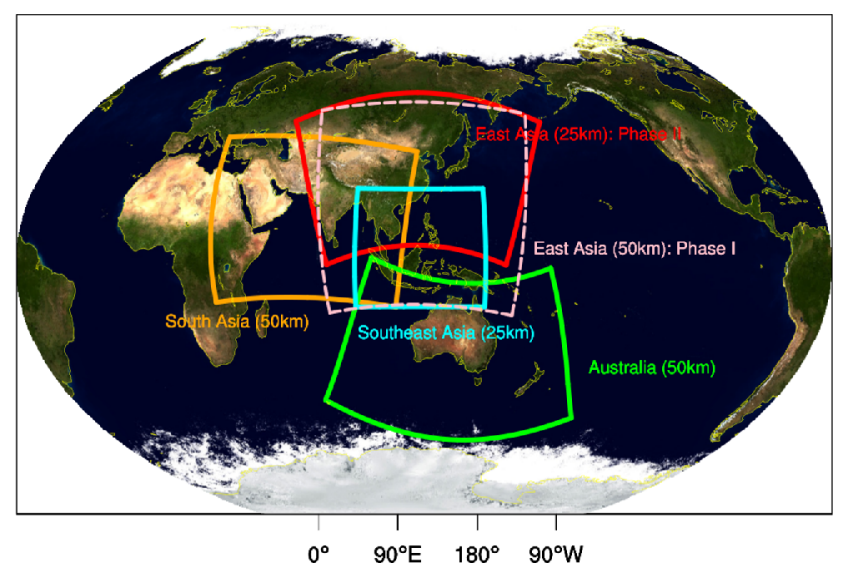

Fig. 1. CORDEX domains and their horizontal resolution over Asia-Pacific Region.

Acknowledgements. We, the guest editors of this issue who are leading coordinators of CORDEX-East Asia, Southeast Asia, and South Asia, are grateful to all authors, reviewers, and editorial office of Korean Meteorological Society (KMS) and Asia-Pacific Journal of Atmospheric Sciences (APJAS).

\section{References}

Christensen, J. H., T. R. Carter, M. Rummukainen, and G. Amanatidis, 2007: Evaluating the performance and utility of regional climate models: the PRUDENCE project. Climatic Change, 81, 1-6.

Dickinson, R. E., R. M. Errico, F. Giorgi, and G. T. Bates, 1989: A regional climate model for the western United States. Climatic Change, 15, 383422.

Fu, C., S. Wang, Z. Xiong, W. J. Gutowski, D.-K. Lee, J. L. McGregor, Y. Sato, H. Kato, J.-W. Kim, and M.-S. Suh, 2005: Regional climate model intercomparison project for Asia. Bull. Amer. Meteor. Soc., 86, 257-266.

Giorgi, F., C. Jones, and G. R. Asrar, 2009: Addressing climate information needs at the regional level: the CORDEX framework. WMO Bull., 58, 175-183.

Stocker, T. F., D. Qin, G.-K. Plattner and M. Tignor, Eds., 2015: Workshop Report of the Intergovernmental Panel on Climate Change Workshop on Regional Climate Projections and their Use in Impacts and Risk Analysis Studies. IPCC Working Group I Technical Support Unit, 171 pp.

Takle, E. S., and Coauthors, 1999: Project to intercompare regional climate simulations (PIRCS): Description and initial results. J. Geophys. Res., 104, D16, 19443-19461. 